\title{
What Influences Educators' Design Preferences for Bullying Prevention Programs? Multi-level Latent Class Analysis of a Discrete Choice Experiment
}

\author{
Charles E. Cunningham ${ }^{1,7} \cdot$. Heather Rimas ${ }^{1} \cdot$ Tracy Vaillancourt $^{2} \cdot$ Bailey Stewart $^{1} \cdot$ Ken Deal $^{3}$. \\ Lesley Cunningham ${ }^{4}$. Thuva Vanniyasingam ${ }^{5}$. Eric Duku ${ }^{1,6}$. Don H. Buchanan ${ }^{4}$. Lehana Thabane ${ }^{5}$
}

Published online: 22 June 2019

(c) The Author(s) 2019

\begin{abstract}
We used a discrete choice conjoint experiment to model the anti-bullying $(\mathrm{AB})$ program preferences of 1080 junior kindergarten to Grade 8 educators. Participants chose between hypothetical AB programs that varied combinations of 12 design attributes. Multi-level latent class analysis yielded three classes: All-in Supervisors (21.5\%) preferred that all teaching staff supervise playgrounds and hallways; Facilitators (61.6\%) preferred that students take ownership of AB activities with 25\% of educators supervising playgrounds and hallways; and Reluctant Delegators (16.9\%) preferred delegating the supervision of playgrounds and hallways to non-teaching staff. This class reported higher dispositional reactance, more implementation barriers, and more psychological reactance to these initiatives. They were less sensitive to social influences and less intent on participating in $\mathrm{AB}$ activities. Multi-level analysis showed a greater proportion of Reluctant Delegators clustered in one of the two groups of schools. The program choices of all classes were sensitive to the support of principals, colleagues, students, and, to a lesser extent, parents. All classes preferred programs conducted from kindergarten through Grade 12 that addressed the problems underlying bullying while valuing firm and consistent consequences for all students. Educators preferred AB programs selected by individual schools, rather than governments.
\end{abstract}

Keywords Bullying $\cdot$ Educator preferences $\cdot$ Discrete choice experiments $\cdot$ Psychological Reactance Theory

\section{Introduction}

Bullying represents the repeated, intentional targeting of students by more powerful peers (Olweus, 1994). Between 10 and $33 \%$ of students report involvement in bullying as a

Electronic supplementary material The online version of this article (https://doi.org/10.1007/s12310-019-09334-0) contains supplementary material, which is available to authorized users.

Charles E. Cunningham

cunningh@mcmaster.ca

1 Department of Psychiatry and Behavioural Neurosciences, Faculty of Health Sciences, McMaster University, 1280 Main St W, Hamilton, ON L8S 4L8, Canada

2 Counselling Psychology, Faculty of Education, University of Ottawa, 145 Jean-Jacques-Lussier, Ottawa, ON K1N 6N5, Canada

3 DeGroote School of Business, McMaster University, 1280 Main St W, Hamilton, ON L8S 4L8, Canada target with 5\% to $13 \%$ acknowledging involvement as perpetrators (Hymel \& Swearer, 2015). Victimization of children and youth by peers is associated with academic difficulties, rejection by peers, low self-esteem, anxiety, and depression (McDougall \& Vaillancourt, 2015). Prospective longitudinal studies show that children and youth victimized by their peers are at increased risk of adult mental health problems (McDougall \& Vaillancourt, 2015). Although anti-bullying (AB) programs yield modest reductions in bullying during

4 Hamilton-Wentworth District School Board, 20 Education Court, Hamilton, ON L9A 0B9, Canada

5 Department of Health Research Methods, Evidence, and Impact, Faculty of Health Sciences, McMaster University, 1280 Main St W, Hamilton, ON L8S 4L8, Canada

6 Offord Centre for Child Studies, McMaster Innovation Park, Suite 201A, 175 Longwood Rd. S, Hamilton, ON L8P 0A1, Canada

7 Ron Joyce Children's Health Centre, 237 Barton Street East, Hamilton, ON L8L 2X2, USA 
the elementary school years (Ttofi \& Farrington, 2011; Yeager, Fong, Lee, \& Espelage, 2015), within-study analyses suggest that the impact of $\mathrm{AB}$ programs beyond middle school is more limited (Yeager et al., 2015).

Fidelity is critical to the implementation and outcome of $A B$ initiatives. In a study of 7413 students, preparation for and adherence to the Finnish KiVa AB program's protocols were associated with class level decreases in student-reported victimization (Haataja et al., 2014). In a US longitudinal study, dosage, a latent variable composed of the percentage of the KiVa program's activities educators completed, the number of lessons conducted, and the time devoted to the program, predicted reductions in self-, teacher-, and peer-reported bullying and victimization (Swift et al., 2017).

The degree to which educators implement and adhere to the protocols of $\mathrm{AB}$ initiatives is associated with a complex set of individual and contextual factors. Implementation, for example, is more successful when programs are supported by head teachers (Ahtola, Haataja, Kärnä, Poskiparta, \& Salmivalli, 2013) and educators are confident in their ability to conduct AP programs (Boulton, 2014). Students report a greater reduction in bullying when teachers are perceived to devote more effort to bullying prevention (Veenstra, Lindenberg, Huitsing, Sainio, \& Salmivalli, 2014).

Educators play a central role in the successful introduction of evidence-based programs; their preferences, therefore, should inform the design, adaptation, and implementation of school-based programs (Damschroder et al., 2009; Durlak \& DuPre, 2008; Powell et al., 2015). Chorpita and colleagues concluded that, “... For treatments to be effective and sustained in practice settings, treatment developers should consider design features that increase the appeal to the therapists who are ultimately responsible for using them." (Chorpita et al., 2015, p. 79). Educators allowed to select a practice consistent with their preferences adopted the intervention more rapidly, implemented the intervention with greater fidelity, and were more likely to sustain the intervention than the non-preference group (Johnson et al., 2014).

Several studies examined educator preferences regarding the strategies that should be included in $\mathrm{AB}$ programs (Bauman, Rigby, \& Hoppa, 2008; Crothers \& Kolbert, 2004). Educators, for example, indicated they would be most likely to employ a disciplinary strategy, enlist the intervention of other adults such as administrators and colleagues, or inform parents that the Behavior must stop (Bauman et al., 2008). In a study of the AB program design and implementation preferences of 1176 junior kindergarten to Grade 8 educators, participants preferred sustainable, universal programs linked closely to the provincial curriculum (Cunningham et al., 2009). They were sensitive to the support of students and staff and valued programs that taught $\mathrm{AB}$ skills to students via lectures, demonstrations, and practice. This study demonstrated the importance of individual differences in the design preferences of educators. Latent class analysis identified three classes with different design preferences: Decision-Sensitive educators who preferred school-based adoption decisions, Support-Sensitive educators who preferred programs selected by local boards of education, and Cost-Sensitive educators who preferred to limit implementation time demands and expenses (Cunningham et al., 2009).

Identifying psychological and demographic factors associated with class membership is an important step in the conduct of latent class analyses (Berlin, Williams, \& Parra, 2014; Zhou, Thayer, \& Bridges, 2018). A number of studies, for example, have reported that the components of the Theory of Planned Behavior are associated with membership in latent classes preferring different approaches to the implementation of school-based mental health services (Cunningham et al., 2009, 2014). This model assumes that the intent to implement $\mathrm{AB}$ programs is linked to the anticipated benefits of these initiatives (Attitudes), social influences encouraging implementation (Subjective Norms), and confidence in one's ability to conduct AB programs (Perceived Behavioral Control). Educators possessing a stronger intent to implement $\mathrm{AB}$ programs would be more likely to actually participate in implementation activities (Behavior). In a previous study, for example, a latent class of Cost Sensitive educators anticipated fewer benefits to $\mathrm{AB}$ programs (Attitudes), more barriers to implementation, and were less intent on participating in $\mathrm{AB}$ activities (Cunningham et al., 2009).

Qualitative studies also point to design and implementation factors influencing the response of educators to $A B$ initiatives (Cunningham et al., 2016). Focus groups with 109 educators, for example, suggested that the effectiveness of $\mathrm{AB}$ programs was influenced by training and follow-up support, competing curriculum demands, difficulty detecting bullying incidents, ineffective responses to bullying, and administrative back-up (Cunningham et al., 2016). Educators felt frustrated by mandated $\mathrm{AB}$ initiatives, limited opportunities to participate in program design, inflexible protocols, and the seemingly arbitrary process via which schools replaced promising programs. Some felt cynical, limited their commitment to $\mathrm{AB}$ programs, selectively implemented components of $\mathrm{AB}$ initiatives, introduced modifications, or resisted implementation. These responses are consistent with Psychological Reactance Theory which suggests that program design and implementation processes limiting decision control might elicit responses that, although intended to retain or reassert personal agency, may undermine prevention initiatives (Brehm \& Brehm, 1981; Rosenberg \& Siegel, 2017). Psychological reactance has been observed in college classrooms (Ball \& Goodboy, 2014), experimental prevention analogues (Legault, Gutsell, \& Inzlicht, 2011), 
and the implementation of evidence-based practices (Gunter \& Whittal, 2010). It is considered a potential challenge to the implementation of prevention programs.

\section{The Current Study}

This study addressed several gaps in the extant literature. First, given the role that educators play in the delivery of school-based initiatives, it is important to increase our understanding of their preference for, and response to, different approaches to the design and implementation of $\mathrm{AB}$ programs. The current study used a discrete choice conjoint experiment (DCE) to extend research on the $\mathrm{AB}$ design preferences of educators. These methods, used by marketing researchers (Orme, 2014) and health economists (de Bekker-Grob, Ryan, \& Gerard, 2012), are increasingly applied to estimate the relative value of the components of school-based prevention initiatives and to "tailor" the implementation of children's mental health services to the professionals responsible for conducting these programs (Powell et al., 2015). DCEs define educational programs as a set of features or attributes (Orme, 2014). The attributes of an $\mathrm{AB}$ program might include the program selection process, quality of the supporting evidence, training time demands, or number of supervisors monitoring playgrounds and hallways. Consistent with Random Utility Theory, DCEs assume that preference for an $\mathrm{AB}$ program is a function of the utility or value of that program's individual attributes plus an error term (Hauber et al., 2016). Each of the attributes included in a DCE is defined by several levels. The three levels of an attribute named "selection process," for example, might include selected by governments, selected by local boards of education, or selected by individual schools. To estimate the relative value of the attributes of a program, DCEs present choices between hypothetical programs created by experimentally combining the levels of different attributes (see Fig. 1).

DCEs can advance educational research in several ways. First, as discussed previously (Cunningham et al., 2014), choosing multi-component options approximates the complexity of real-world educational decision making (Orme, 2014; Phillips, Johnson, \& Maddala, 2002); DCEs are more likely to elicit the simplifying heuristics influencing educational decisions (Hauser, 2014; Orme, 2014). Second, given the multi-component design of effective $\mathrm{AB}$ programs (Olweus, 1994; Ttofi \& Farrington, 2011), competing curriculum demands, and cost constraints, program planners and the educators implementing $\mathrm{AB}$ programs must consider trade-offs. Increasing the time devoted to one component of the program, for example, may limit the time available to others. Rather than rating the individual components of complex programs, an approach allowing participants to rate all features as important, the multi-component choices presented in DCEs require participants to consider these tradeoffs. Third, because informants consider each attribute of an option in context of experimentally manipulated combinations of other attributes, DCEs allow investigators to estimate the relative influence of each feature on $\mathrm{AB}$ program choices (Hauber et al., 2016; Orme, 2014). Fourth, DCEs allow educational program developers to estimate the relative importance of options that do not exist. Quantifying the relative importance of both innovative options and existing practices permits planners to simulate the response of participants to design options under consideration before costly,

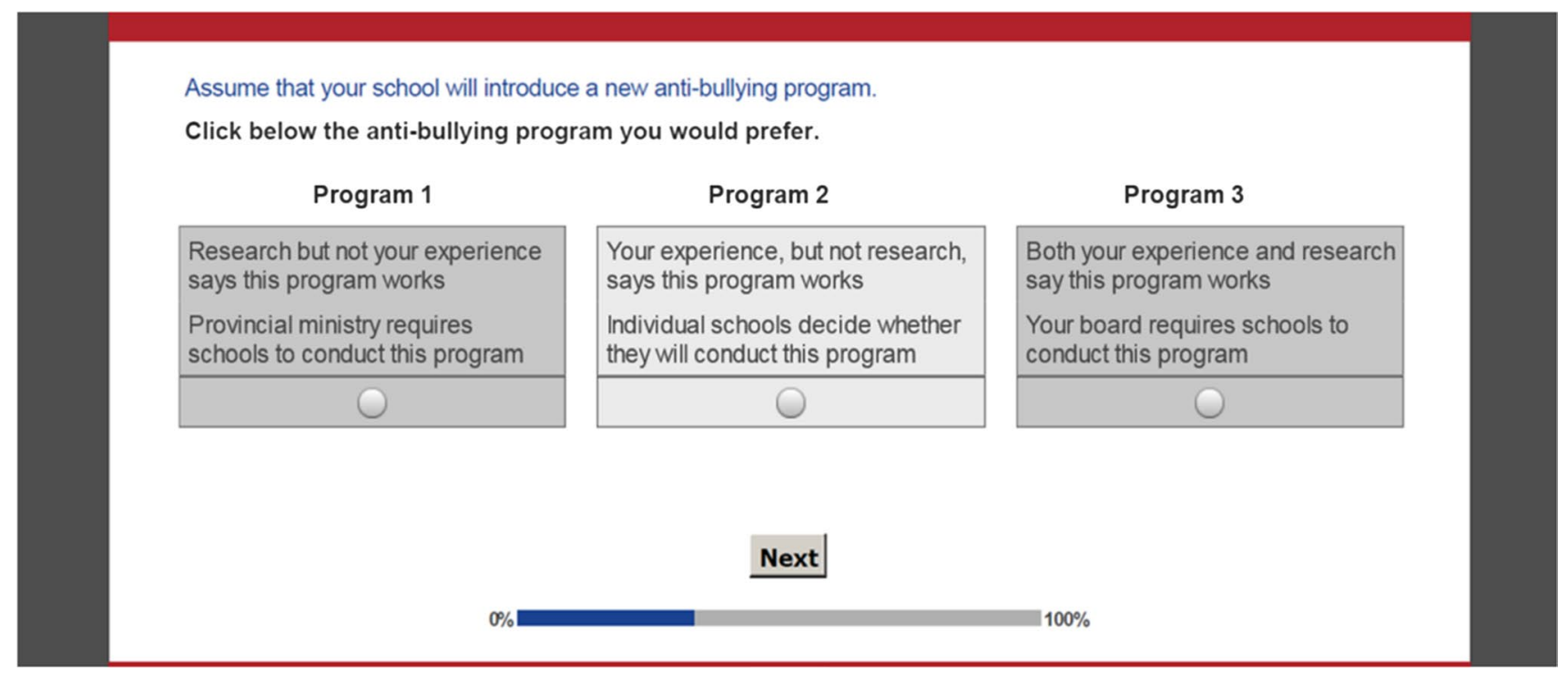

Fig. 1 An example of the 15 choice tasks completed by each participant. Sawtooth Software's experimental design module created 999 combinations of the survey and randomly assigned one version to each participant 
time-intensive implementation projects begin. Finally, responding to multi-component options in DCEs reduces the influence of the social desirability biases (Caruso, Rahnev, \& Banaji, 2009; Phillips et al., 2002) that can influence the response of educators to more traditional rating scales (Larson \& Bradshaw, 2017).

Second, studies using DCEs to examine the program implementation preferences of educators (Cunningham et al., 2009, 2014) have not accounted for the multi-level structure of preference data where educators are nested within schools (Vermunt, 2008). These studies risk overestimating educator influences and neglecting potentially important school-level processes. The current study, therefore, utilized a multi-level approach to the latent class analysis of discrete choice data (Vermunt, 2008).

Third, some educators respond negatively to limitations in the opportunity to influence the selection, design, and implementation of AB programs (Cunningham et al., 2016), a response consistent with Psychological Reactance Theory (Brehm \& Brehm, 1981; Rosenberg \& Siegel, 2017). Although qualitative methods have provided a rich thematic account of the mechanisms via which the design and implementation of $\mathrm{AB}$ programs may elicit psychological reactance, their perspective is limited by small samples, self-presentation biases, difficulty quantifying the relative importance of the themes that emerge, and the absence of a mechanism for estimating the proportion of educators sharing diverging views regarding program design. We are aware of no studies quantifying this potentially important response. The current study extends previous research by asking a large sample of educators to report the extent to which they experienced psychological reactance to the $\mathrm{AB}$ programs in their schools. We measured a more stable tendency to resist persuasive influences (dispositional reactance) and determined the extent to which these measures were linked to membership in latent classes preferring different approaches to $\mathrm{AB}$ program design.

We addressed three research questions:

RQ1. Are there latent classes preferring different approaches to $A B$ program design? Given previous studies (Cunningham et al., 2009), we anticipated latent classes of educators with preferences ranging from supporting the implementation of $\mathrm{AB}$ initiatives to a class less inclined to participate. We estimated the relative influence of 12 design attributes on the $\mathrm{AB}$ program choices of participants in each latent class. Based on earlier studies (Cunningham et al., 2009), we predicted that the social context in which $A B$ programs are implemented (e.g., the response of colleagues and principals) would exert an important influence on $\mathrm{AB}$ program choices.

RQ2. Is the Theory of Planned Behavior linked to latent class membership? Psychological measures can predict and explain membership in unobserved latent classes, inform the content of advertising strategies and health communication messages, and enable implementation teams to tailor AB programs to local contexts (Zhou et al., 2018). We predicted that latent classes anticipating more benefits to $\mathrm{AB}$ programs (Attitudes) would be more amenable to social influences encouraging participation (Subjective Norms), express greater confidence in their ability to participate (Perceived Behavioral Control), identify fewer barriers to implementation, and reside in latent classes that were more intent on participating.

RQ3. Is psychological reactance linked to latent class membership? We extend qualitative research (Cunningham et al., 2016) by asking educators to indicate the extent to which they experienced different types of psychological reactance and measured variation in dispositional reactance, a more general tendency to resist persuasive efforts. We predicted that educators reporting higher dispositional reactance and greater psychological reactance to $\mathrm{AB}$ programs would reside in latent classes that were less intent on participating in $\mathrm{AB}$ activities.

\section{Method}

\section{Participants}

The Hamilton Integrated Research Ethics Board and the participating school boards approved this study. Educators (Table 1) were from a Canadian community of 530,000 residents. We grouped schools into five areas with differing demographics and randomly selected schools from each area. Administrators e-mailed a letter describing the study to the principals at 80 schools. Of the 70 principals we were able to contact, 48 agreed to participate. The areas of the city in which participating $\left(X_{\mathrm{P}}\right)$ and nonparticipating $\left(X_{\mathrm{NP}}\right)$ schools were located did not differ with respect to urban versus rural locations $\left(X_{\mathrm{p}}\right.$ urban $=89.6 \%$ $X_{\mathrm{NP}}$ urban $\left.=93.8 \%, X^{2}(1, N=80)=417, p=.518\right)$. Supplementary electronic Table 1 shows that median family income, adults over 25 without a high school or postsecondary diploma, percentage aged 25 to 64 with a university diploma or degree, households headed by female lone parents, or percentage of immigrants did not differ, and that regional demographics were very similar to our sample area (DeLuca, Johnston, \& Buist, 2012).

We sent links to 1313 potential participants present on the day the survey was administered at each school. All members of the school staff present (e.g., teachers, principals, educational assistants, etc.) were eligible to participate. Of those receiving the link, 12 elected not to participate, 221 discontinued the survey, and 1080 completed surveys. 
Table 1 Demographic comparisons of the three classes of educators

\begin{tabular}{|c|c|c|c|c|c|c|c|}
\hline & \multirow[t]{2}{*}{$N$} & \multirow[t]{2}{*}{$\%$} & \multicolumn{5}{|l|}{ Latent class } \\
\hline & & & Supervisors & Facilitators & Delegators & $\chi^{2}$ & $d f$ \\
\hline Sample size & 1080 & 100 & 233 & 665 & 182 & & \\
\hline Percentage & & 100.0 & 21.6 & 61.6 & 16.9 & & \\
\hline Age & & & & & & 7.25 & 6 \\
\hline $18-29$ years & 123 & 11.4 & 28.5 & 57.7 & 13.8 & & \\
\hline 30-39 years & 365 & 33.8 & 21.1 & 60.5 & 18.4 & & \\
\hline $40-49$ years & 358 & 33.1 & 18.4 & 64.0 & 17.6 & & \\
\hline 50 years or older & 234 & 21.7 & 23.5 & 61.5 & 15.0 & & \\
\hline Sex & & & & & & $7.43^{\mathrm{a}}$ & 2 \\
\hline Male & 203 & 18.8 & 26.6 & 53.2 & 20.2 & & \\
\hline Female & 877 & 81.2 & 20.4 & 63.5 & 16.1 & & \\
\hline Education & & & & & & $55.74^{\mathrm{c}}$ & 8 \\
\hline High school or less & 5 & 0.5 & 60.0 & 40.0 & 0.0 & & \\
\hline College or university courses & 16 & 1.5 & 56.3 & 43.8 & 0.0 & & \\
\hline College diploma or degree & 138 & 12.8 & 38.4 & 56.5 & 5.1 & & \\
\hline Bachelor's degree & 728 & 67.4 & 19.0 & 62.4 & 18.7 & & \\
\hline Master's or doctoral degree & 193 & 17.9 & 15.5 & 64.2 & 20.2 & & \\
\hline Profession & & & & & & $56.57^{\mathrm{c}}$ & 6 \\
\hline Administrator, Principal, or Vice Principal & 38 & 3.5 & 18.4 & 71.1 & 10.5 & & \\
\hline Teacher or learning resource teacher & 869 & 80.5 & 18.1 & 62.3 & 19.7 & & \\
\hline Educational assistants & 168 & 15.6 & 39.3 & 56.5 & 4.2 & & \\
\hline Support staff & 5 & 0.5 & 60.0 & 40.0 & 0.0 & & \\
\hline \multicolumn{8}{|l|}{ Teaching experience (check all that apply) } \\
\hline Junior/senior kindergarten & 401 & 37.2 & 20.9 & 67.6 & 11.5 & $14.77^{\mathrm{b}}$ & 2 \\
\hline Grades $1-5$ & 677 & 62.7 & 20.4 & 61.3 & 18.3 & 3.35 & 2 \\
\hline Grades $6-8$ & 481 & 44.6 & 20.8 & 62.4 & 16.8 & 0.28 & 2 \\
\hline Grades 9-12 & 29 & 2.7 & 34.5 & 55.2 & 10.3 & 3.29 & 2 \\
\hline Years of experience & & & & & & 9.27 & 10 \\
\hline $0-5$ years & 175 & 16.2 & 27.4 & 60.0 & 12.6 & & \\
\hline $6-10$ years & 267 & 24.7 & 20.6 & 61.8 & 17.6 & & \\
\hline $11-15$ years & 246 & 22.8 & 22.4 & 58.1 & 19.5 & & \\
\hline $16-20$ years & 161 & 14.9 & 19.3 & 63.4 & 17.4 & & \\
\hline $21-25$ years & 103 & 9.5 & 18.4 & 63.1 & 18.4 & & \\
\hline More than 25 years & 127 & 11.8 & 18.9 & 66.9 & 14.2 & & \\
\hline
\end{tabular}

Supervisors All-in Supervisors; Facilitators Facilitators; Delegators Reluctant Delegators ${ }^{\mathrm{a}} p<0.05 ;{ }^{\mathrm{b}} p<0.01 ;{ }^{\mathrm{c}} p<0.001$

\section{Designing the Discrete Choice Conjoint Experiment}

The study's discrete choice experiment was developed in several steps.

\section{Selecting Attributes}

As per guidelines, we derived attributes of $A B$ programs via a qualitative process (Bridges et al., 2011). We conducted 19 focus groups with 103 elementary and middle school educators. Focus group methods and findings are detailed in another publication (Cunningham et al., 2016). Using Nvivo software, we coded transcripts thematically. We selected attributes that were repeatedly discussed (recurrent themes) as influencing the implementation or outcome of the $\mathrm{AB}$ programs in their schools. For example, the attribute "Principal Support" was discussed in $84 \%$ of the 19 focus groups. As one participant stated, "if the principal doesn't buy into it you're not going to get everybody on board." (Cunningham et al., 2016). The attribute Colleague Support and Engagement was a topic of discussion in $63.2 \%$ of focus groups. For example, "There will be recidivism no matter what if you do not have the entire staff on board..." (Cunningham et al., 2016). Because the number of attributes that can be included 
in DCEs is limited (Bridges et al., 2011; Orme, 2014), a team with content expertise (e.g., educational researchers, school social worker, school consultant) used a consensual process to reduce potential attributes to a final set of 12 . As recommended (Bridges et al., 2011; Orme, 2014), we included some attributes that proved influential in previous studies (e.g., Colleague Support and Engagement) or, like Recess Supervision, were linked to the outcome of AB programs (Ttofi \& Farrington, 2011). We selected attributes that were relatively independent of one another and could be modified to improve implementation (Bridges et al., 2011; Orme, 2014). Attributes included the support and engagement of principals, colleagues, students, and parents, the extent to which programs focused on bullying versus underlying problems, supervision of playgrounds and hallways at recess, rewards for student prevention, consistent and firm consequences, the extent to which $\mathrm{AB}$ programming extended across grades, supporting evidence, decision control, and time for learning and implementation.

\section{Specifying Attribute Levels}

Each attribute was described by four levels. This design avoids a bias in favor of attributes with a greater number of levels (Orme, 2014; Wittink, Krishnamurthi, \& Reibstein, 1990). For example, the levels of the attribute "Rewards Student Prevention" were: (1) rarely rewards student who prevent bullying, (2) sometimes rewards students who prevent bullying, (3) often rewards students who prevent bullying, or (4) always rewards students who prevent bullying. The survey was piloted to ensure that attributes were easily understood and combined logically in choice tasks (Orme, 2014). Attributes and their levels are presented in Table 2.

\section{Designing Choice Sets}

Sawtooth Software's experimental design algorithm created 999 sets of choice tasks with different combinations of the study's attribute levels (Johnson et al., 2013). One set was randomly assigned to each participant. Each choice set presented a warm-up choice task introducing this method, 15 experimental choice tasks (see Fig. 1), and two holdout choice tasks to examine internal validity. Each choice task presented three hypothetical AB programs. According to a partial profile experimental design, each $\mathrm{AB}$ program was described by the levels of two of the study's 12 attributes (Chrzan, 2010; Orme, 2014). Rather than presenting choices between options described by 12 attributes, partial profile designs present choices between options described by a subset of the study's attributes. By simplifying choice tasks, partial profile designs reduce the impact of dominant attributes, encourage participants to weigh the incremental contribution of less important features of the program, and improve predictive validity (Chrzan, 2010). Participants were instructed to, "Assume that your school will introduce a new anti-bullying program. Click below the anti-bullying program you would prefer."

\section{Measuring Factors Linked to Latent Class Membership}

\section{Theory of Planned Behavior}

To address RQ2, we composed a set of questions based on the Theory of Planned Behavior (Ajzen, 1991), a model that has been linked to the implementation of $A B$ programs in previous studies (Cunningham et al., 2009). Participants completed the five-point Likert questions $(1=$ Strongly Disagree to $5=$ Strongly Agree) described below. To measure Attitudes, five questions examined the anticipated benefits of $\mathrm{AB}$ programs (e.g., Reduce the number of students who are victims of bullying), $\alpha=0.93$. To measure Subjective Norms, six questions measured the influence of different individuals and organizations on the decision to participate in $\mathrm{AB}$ programs (e.g., My teaching colleagues; The principal at my school), $\alpha=0.89$. To measure Perceived Behavioral Control, five questions examined confidence in one's ability to implement and conduct $\mathrm{AB}$ programs (e.g., I have the confidence to prevent or respond to bullying), $\alpha=0.89$. Barriers, a component of Perceived Behavioral Control, was measured by five questions describing factors that may compromise implementation (e.g., Too many other programs to conduct), $\alpha=0.84$. Although barriers are typically considered a component of Perceived Behavioral Control, studies finding that this measure contributed independently to the prediction of intentions (and Behavior) recommended measuring barriers separately (Bozionelos \& Bennett, 1999). Six questions measured the Intent to participate in different activities linked to the implementation of $\mathrm{AB}$ programs (e.g., I would be willing to participate in a 1-day workshop teaching skills to prevent bullying), $\alpha=0.79$. For all scales, responses to individual questions were summed to yield a total score.

\section{Psychological Reactance}

To address RQ3, eight questions $(1=$ never, $2=$ once a year, $3=$ once a month, $4=$ once a week, and $5=$ once a day) derived from focus groups (Cunningham et al., 2016) measured cognitive, affective, and behavioral responses consistent with Psychological Reactance Theory (e.g., Felt cynical about AB programs; Told your colleagues $\mathrm{AB}$ programs 
Table 2 Zero-centered utility coefficients and $Z$ value comparisons for the three classes of educators

\begin{tabular}{|c|c|c|c|c|c|c|c|}
\hline \multirow{3}{*}{$\begin{array}{l}\text { Attribute } \\
\text { Content of attribute levels }\end{array}$} & \multicolumn{6}{|c|}{ Latent class } & \multirow[t]{3}{*}{ Wald } \\
\hline & \multicolumn{2}{|c|}{ Supervisors } & \multicolumn{2}{|c|}{ Facilitators } & \multicolumn{2}{|c|}{ Delegators } & \\
\hline & $U$ & $Z$ & $U$ & $Z$ & $U$ & $Z$ & \\
\hline Principal Support & & & & & & & $172.64^{\mathrm{c}}$ \\
\hline Principal does not champion this program and does not back teachers up & -0.61 & -5.68 & -1.95 & -14.92 & -1.17 & -5.85 & \\
\hline Principal champions this program but does not back teachers up & -0.22 & -2.37 & -1.06 & -10.14 & -0.89 & -5.00 & \\
\hline Principal does not champion this program but does back teachers & -0.15 & -1.53 & 0.75 & 9.42 & 0.31 & 2.22 & \\
\hline Principal champions this program and backs teachers up & 0.98 & 11.13 & 2.26 & 25.56 & 1.75 & 12.01 & \\
\hline Consistency across grades & & & & & & & $50.43^{\mathrm{c}}$ \\
\hline Runs in kindergarten but discontinued in Grade 1 & -1.04 & -7.61 & -2.14 & -16.90 & -1.33 & -6.67 & \\
\hline Runs from kindergarten to Grade 5 and then discontinued & -0.61 & -5.14 & -0.44 & -5.27 & -0.14 & -0.99 & \\
\hline Runs from kindergarten to Grade 8 and then discontinued & 0.54 & 5.60 & 0.98 & 13.87 & 0.44 & 3.36 & \\
\hline Runs from kindergarten to Grade 12 & 1.11 & 11.14 & 1.59 & 20.66 & $\mathbf{1 . 0 3}$ & 7.47 & \\
\hline Student engagement in $A B$ programs & & & & & & & $164.24^{\mathrm{c}}$ \\
\hline Students resist participating in this program & -0.75 & -6.90 & -1.62 & -13.50 & -1.69 & -7.08 & \\
\hline Students just go through the motions with this program & -0.45 & -4.22 & -1.68 & -13.97 & -0.67 & -3.54 & \\
\hline Students actively participate in this program & 0.74 & 8.33 & 1.53 & 18.91 & 1.14 & 7.94 & \\
\hline Students take ownership of this program & 0.47 & 4.94 & 1.77 & 21.10 & 1.21 & 7.78 & \\
\hline Colleague Support and Engagement & & & & & & & $138.48^{\mathrm{c}}$ \\
\hline Your colleagues don't like or participate in this program & -0.48 & -4.60 & -1.36 & -14.84 & -1.07 & -6.03 & \\
\hline Your colleagues like but don't participate in this program & -0.12 & -1.21 & -0.47 & -5.93 & 0.21 & 1.59 & \\
\hline Your colleagues participate in but don't like this program & -0.13 & -1.35 & -0.17 & -2.14 & -0.55 & -3.44 & \\
\hline Your colleagues like and participate in this program & 0.73 & 7.87 & 1.99 & 26.43 & 1.41 & 9.79 & \\
\hline Consistent and firm consequences & & & & & & & $184.90^{\mathrm{c}}$ \\
\hline Consequences are not consistent for all students nor firm enough & -0.27 & -2.78 & -1.78 & -15.61 & -0.97 & -5.61 & \\
\hline Consequences are consistent for all students but not firm enough & -0.20 & -2.13 & -0.01 & -0.18 & -0.73 & -4.71 & \\
\hline Consequences are firm enough but not consistent for all students & 0.04 & 0.46 & -0.10 & -1.19 & 0.39 & 2.94 & \\
\hline Consequences are firm enough and consistent for all students & $\mathbf{0 . 4 2}$ & 4.42 & 1.89 & 23.14 & 1.30 & 8.84 & \\
\hline Focus on underlying problems versus bullying & & & & & & & $73.76^{\mathrm{c}}$ \\
\hline Focuses $100 \%$ on problems underlying bullying and $0 \%$ on bullying & -0.06 & -0.62 & -0.86 & -9.44 & -0.44 & -2.68 & \\
\hline Focuses $67 \%$ on problems underlying bullying and $33 \%$ on bullying & 0.68 & 7.45 & 1.36 & 18.66 & 0.57 & 3.97 & \\
\hline Focuses $33 \%$ on problems underlying bullying and $67 \%$ on bullying & 0.44 & 4.76 & 0.87 & 12.15 & 0.43 & 3.03 & \\
\hline Focuses $0 \%$ on problems underlying bullying and $100 \%$ on bullying & -1.06 & -8.16 & -1.37 & -14.27 & -0.56 & -3.31 & \\
\hline Supporting evidence & & & & & & & $126.34^{\mathrm{c}}$ \\
\hline Neither your experience nor research says this program works & -0.08 & -0.88 & -1.33 & -13.37 & -0.78 & -4.97 & \\
\hline Research but not your experience says this program works & -0.15 & -1.66 & -0.21 & -2.76 & -0.24 & -1.75 & \\
\hline Your experience, but not research, says this program works & 0.02 & 0.27 & 0.12 & 1.73 & 0.25 & 1.93 & \\
\hline Both your experience and research say this program works & 0.21 & 2.30 & 1.41 & 18.81 & 0.77 & 6.14 & \\
\hline Parental support and engagement & & & & & & & $72.02^{\mathrm{c}}$ \\
\hline Parents don't participate in or like this program & -0.33 & -3.24 & -1.19 & -12.99 & -0.88 & -5.61 & \\
\hline Parents participate in this program but don't like it & -0.27 & -2.78 & -0.36 & -4.83 & -0.35 & -2.36 & \\
\hline Most parents like this program but don't participate & 0.15 & 1.61 & 0.23 & 3.32 & 0.09 & 0.76 & \\
\hline Most parents participate in and like this program & 0.46 & 5.08 & 1.33 & 18.94 & 1.13 & 8.21 & \\
\hline Time for learning and implementation & & & & & & & $234.27^{\mathrm{c}}$ \\
\hline You don't have enough time to fully learn or fully implement this program & 0.23 & 2.58 & -1.43 & -13.25 & -0.89 & -5.30 & \\
\hline You have enough time to fully implement but not to fully learn this program & -0.30 & -3.06 & -0.20 & -2.60 & -0.15 & -1.03 & \\
\hline You have enough time to fully learn this program but not to fully implement & 0.03 & 0.33 & 0.05 & 0.75 & -0.14 & -0.95 & \\
\hline You have enough time to fully learn and fully implement this program & 0.04 & 0.42 & 1.57 & 20.23 & 1.17 & 7.66 & \\
\hline Rewards for student prevention & & & & & & & $64.29^{c}$ \\
\hline Rarely rewards students who prevent bullying & -0.46 & -4.60 & -1.30 & -14.20 & -0.43 & -2.78 & \\
\hline
\end{tabular}


Table 2 (continued)

\begin{tabular}{|c|c|c|c|c|c|c|c|}
\hline \multirow{3}{*}{$\begin{array}{l}\text { Attribute } \\
\text { Content of attribute levels }\end{array}$} & \multicolumn{6}{|c|}{ Latent class } & \multirow[t]{3}{*}{ Wald } \\
\hline & \multicolumn{2}{|c|}{ Supervisors } & \multicolumn{2}{|c|}{ Facilitators } & \multicolumn{2}{|c|}{ Delegators } & \\
\hline & $U$ & $Z$ & $U$ & $Z$ & $U$ & $Z$ & \\
\hline Sometimes rewards students who prevent bullying & -0.06 & -0.61 & -0.12 & -1.70 & 0.13 & 1.05 & \\
\hline Often rewards students who prevent bullying & 0.01 & 0.14 & 0.72 & 10.50 & 0.24 & 1.91 & \\
\hline Always rewards students who prevent bullying & 0.51 & 5.75 & 0.70 & 9.95 & 0.05 & 0.37 & \\
\hline Recess Supervision & & & & & & & $361.14^{\mathrm{c}}$ \\
\hline Non-teaching staff supervise playgrounds and hallways at every recess & -0.68 & -5.05 & -0.75 & -6.94 & 2.23 & 11.40 & \\
\hline $25 \%$ of educators must supervise playgrounds and hallways at every recess & 0.04 & 0.42 & 0.93 & 12.56 & 0.93 & 4.67 & \\
\hline $50 \%$ of educators must supervise playgrounds and hallways at every recess & 0.24 & 2.62 & 0.37 & 5.04 & -0.92 & -4.28 & \\
\hline All educators must supervise playgrounds and hallways at every recess & 0.39 & 3.92 & -0.55 & -5.86 & -2.25 & -5.41 & \\
\hline Decision control & & & & & & & $25.17^{\mathrm{c}}$ \\
\hline Provincial ministry requires schools to conduct this program & -0.11 & -1.20 & -0.24 & -3.34 & -0.22 & -1.44 & \\
\hline Your board requires schools to conduct this program & -0.01 & -0.15 & 0.21 & 3.15 & -0.54 & -3.31 & \\
\hline Individual schools decide whether they will conduct this program & 0.18 & 1.97 & $\mathbf{0 . 3 4}$ & 5.09 & 0.48 & 3.31 & \\
\hline Individual educators decide whether they will conduct this program & -0.05 & -0.55 & -0.32 & -4.36 & 0.28 & 1.90 & \\
\hline
\end{tabular}

For each attribute, the highest utility for each segment is bolded. Utility coefficients with $Z$ values $>1.95$ differ significantly from zero Wald measures the statistical significance of the differences in the utility coefficients of the three classes; Supervisors All-in Supervisors; Facilitators Facilitators; Delegators Reluctant Delegators

${ }^{\mathrm{c}} p<0.001$

are not working). Responses to individual questions were summed to yield a total score, $\alpha=0.90$.

\section{Dispositional Reactance}

The 14-question ( $1=$ Strongly Disagree, $5=$ Strongly Agree) Hong Dispositional Reactance Scale (Shen \& Dillard, 2005) measured a tendency to resist persuasive efforts (e.g., "I resist the attempts of others to influence me"). Responses to individual questions were summed to yield a total score, $\alpha=0.89$.

\section{Demographics}

Respondents recorded their sex, years of educational experience, experience teaching different grades, etc. (Table 1).

\section{Procedure}

After endorsing an electronic consent, participants completed anonymous online surveys on computers at their schools. The software did not record IP addresses. Participants read the provincial Ministry of Education's definition of bullying, answered Theory of Planned Behavior questions, and responded to DCE choice tasks, demographic questions, and measures of psychological reactance. Those completing the survey were given the option of entering a draw for one of the twelve $\$ 50.00$ gift certificates to a national bookstore. Median time to complete the survey was $16.6 \mathrm{~min}$.

\section{Data Analysis}

\section{Fitting a Latent Class Model}

To address RQ1, we used multi-level latent class analysis (Latent Gold Choice 5.1) to estimate a three-level model (Vermunt, 2008). To enable multi-level latent class analyses, we generated an anonymous code for the surveys in each school. The actual identify of the school was not linked to survey data. The 15 choices (Level 1) were nested within educators (Level 2), who were nested within schools (Level 3) (Vermunt, 2008). At Level 2, we estimated discrete random effects models specifying from 1 to 8 latent classes of educators (Hauber et al., 2016). At Level 2, latent classes comprise clusters of educators preferring different approaches to the design or implementation of $\mathrm{AB}$ programs. Next, we estimated from 1 to 3 latent classes of schools (Level 3) as discrete random effects (Vermunt, 2008). Latent classes at Level 3 comprise clusters of schools in which the proportion of educators in Level 2 latent classes preferring different approaches to the design of $\mathrm{AB}$ programs varies. For example, one Level 3 latent class of schools might have a greater proportion of educators in Level 2 latent classes preferring that individual schools select AB programs. Another Level 3 latent class might have a greater proportion of educators in latent classes preferring that the ministry of 
education selects $\mathrm{AB}$ programs. To avoid an unrepresentative local solution, we computed each model 250 times from semi-random starting points and retained the best fitting model (Berlin et al., 2014; Hauber et al., 2016; Nylund, Asparouhov, \& Muthén, 2007; Vermunt \& Magidson, 2005). Decisions regarding the number of latent classes to retain at Levels 2 and Level 3 were based on fit indices (e.g., Bayesian Information Criterion (BIC)), latent class size, and conceptual utility (Berlin et al., 2014; Lanza \& Rhoades, 2013; Zhou et al., 2018). Educators at Level 2 and schools at Level 3 were assigned to a latent class with the highest posterior probability of group membership (Hauber et al., 2016; Vermunt, 2008; Zhou et al., 2018).

\section{Estimating Utility Coefficients}

Analysis integrated latent class and conditional logit to fit zero-centered utility coefficients to effects-coded data for each latent class (Hauber et al., 2016; Vermunt, 2008; Zhou et al., 2018). Higher utility coefficients reflect a stronger preference in comparison with other levels of that attribute.

\section{Calculating Relative Importance Scores}

We derived importance scores reflecting the proportion of variation in Level 2 utility coefficients accounted for by variation in the levels of each attribute (Orme, 2014; Vermunt, 2008). For each latent class, the range of each attribute's utility coefficients (high minus low) was summed to yield a total range. Each attribute's range was divided by the total range and multiplied by 100 to yield a percentage. Higher importance scores mean that variation in the levels of an attribute exerted a greater influence on program choices.

\section{Identifying Factors associated with Latent Class Membership}

To address RQ2 and RQ3, we computed one-way multivariate analysis of variance (MANOVAs) determining whether the components of the Theory of Planned Behavior and measures of psychological and dispositional reactance differed as a function of latent class membership. When overall tests in MANOVAs were significant, we computed univariate analysis of variance (ANOVAs) followed by post hoc Dunnett's C comparisons. The criterion for statistical significance was set apriori at alpha $=0.05$. These analyses were performed using SPSS version 25.

\section{Results}

RQ1. Are there latent classes of educators preferring different approaches to AB program design? A three-class solution (Supplementary Table 2) yielded the lowest BIC, classes with a relatively large number of participants, and a conceptually useful model (Lanza \& Rhoades, 2013). Although the addition of two school-level classes to the model increased BIC, it reduced Akaike Information Criterion (AIC), a less conservative fit index (Dziak, Coffman, Lanza, Li, \& Jermiin, 2019). We labeled the classes as Allin Supervisors (21.5\%), Facilitators (61.6\%), and Reluctant Delegators (16.9\%). Multi-level findings (Supplementary Electronic Table 3) show the probability that the educators in each of Level 3's two classes of schools were members of Level 2's three classes of educators. At the level of schools, a two-class solution assigned $61 \%$ of schools to Class 1 and $39 \%$ of schools to Class 2. In comparison with school Class 2 , a greater proportion of school Class 1's educators (26\% vs. 3\%) were Reluctant Delegators. A greater proportion of Class 2's educators were Facilitators (69\% vs. 52\%). Zerocentered utility coefficients are presented in Table 2 in order of their relative importance to All-in Supervisors. Supplementary Electronic Table 4 shows that educators in the Level 3 class of schools with a greater proportion of Reluctant Delegators (school Class 1) reported higher dispositional reactance, more psychological reactance, were less likely to be influenced by social norms, and less confident in their ability to implement AB programs.

All-in Supervisors (21.5\%). This class preferred that $100 \%$ of educators supervised playgrounds and hallways at every recess (Table 2). They preferred that students actively participate in the program and that those preventing bullying were always rewarded. Consistency across grades and a focus on both bullying and the underlying contributors to this problem were particularly important to this class (Table 3). The quality of the evidence supporting program effectiveness, in contrast, exerted little influence on their choices.

Facilitators (61.6\%). Facilitators preferred that $25 \%$ of educators supervise playgrounds and hallways with students taking ownership of AB programs (Table 2). They preferred that students preventing bullying were often rewarded. Programs extending from kindergarten to Grade 12 exerted more influence on choices than any other design attribute (Table 3). Time for learning and implementation exerted a moderately important influence on program choices (Table 3).

Reluctant Delegators (16.9\%). Reluctant Delegators preferred that non-teaching staff supervised playgrounds and hallways (Table 2). Variation in responsibility for playground and hallway supervision exerted a greater influence 
Table 3 Relative importance of $\mathrm{AB}$ program design attributes to three classes of educators

\begin{tabular}{|c|c|c|c|c|c|c|}
\hline \multirow[b]{3}{*}{ Attributes } & \multicolumn{6}{|c|}{ Latent class } \\
\hline & \multicolumn{2}{|c|}{ Supervisors } & \multicolumn{2}{|c|}{ Facilitators } & \multicolumn{2}{|c|}{ Delegators } \\
\hline & $R$ & $I$ & $R$ & $I$ & $R$ & $I$ \\
\hline Consistency across grades & 1 & 16.7 & 2 & 11.1 & 5 & 9.1 \\
\hline Focus on underlying problems versus bullying & 2 & 13.5 & 8 & 8.1 & 10 & 4.4 \\
\hline Principal support & 3 & 12.4 & 1 & 12.5 & 2 & 11.3 \\
\hline Student engagement in $\mathrm{AB}$ programs & 4 & 11.6 & 4 & 10.2 & 3 & 11.2 \\
\hline Colleague support and engagement & 5 & 9.4 & 5 & 9.9 & 4 & 9.6 \\
\hline Recess Supervision & 6 & 8.3 & 11 & 5.0 & 1 & 17.3 \\
\hline Rewards for student prevention & 7 & $\mathbf{7 . 5}$ & 10 & 6.0 & 12 & 2.6 \\
\hline Parental support and engagement & 8 & 6.1 & 9 & 7.5 & 8 & 7.8 \\
\hline Consistent and firm consequences & 9 & 5.3 & 3 & 10.9 & 6 & 8.8 \\
\hline Time for learning and implementation & 10 & 4.2 & 6 & 8.9 & 7 & 8.0 \\
\hline Supporting evidence & 11 & 2.8 & 7 & 8.1 & 9 & 6.0 \\
\hline Decision control & 12 & 2.3 & 12 & 2.0 & 11 & 3.9 \\
\hline
\end{tabular}

Attributes are ranked in order of their importance to the All-in Supervisors class. $R$ Rank of each attribute's importance within each class; $I$ Relative importance of each attribute expressed as a percentage of the total variability (high to low) across utility coefficients. Within each class, importance scores add to 100.0 with the highest score for each attribute bolded. Variation in the levels of attributes with higher importance scores exerts a greater influence on program design choices. Supervisors All-in Supervisors; Facilitators Facilitators; Delegators Reluctant Delegators on this class's choices than any other design attribute (Table 3). Although they preferred that students took ownership of the program, rewarding those who prevented bullying was of lower importance than any other attribute.

Shared preferences. Educators agreed on a significant proportion of the study's design features. Variation in the support and engagement of principals, colleagues, and students exerted an important influence on program choices of all classes of educators (Table 3). All classes preferred programs championed by principals who backed teachers up (Table 2). Educators preferred principals who backed them up more than those who simply championed programs.
Educators were more likely to choose AB programs which colleagues, students, and to a lesser extent parents liked and participated in. When considering the levels of parental involvement, educators valued programs that parents liked more than those that parents participated in. All classes preferred $\mathrm{AB}$ programs running from kindergarten through Grade 12. Educators chose programs supported by both personal experience and research. Given a choice between programs backed by research versus those supported by personal experience, however, most would base decisions on their experience. All classes preferred AB programs that focused $67 \%$ on problems underlying bullying and $33 \%$ on
Table 4 Theory of Planned Behavior and psychological reactance scales comparisons for the three classes

\begin{tabular}{|c|c|c|c|c|c|c|c|c|c|c|}
\hline \multirow[t]{3}{*}{ Variable } & \multicolumn{6}{|c|}{ Latent class } & \multirow[t]{3}{*}{$F$} & \multirow[t]{3}{*}{$p$} & \multirow[t]{3}{*}{$C$} & \multirow[t]{3}{*}{$\eta^{2}$} \\
\hline & \multicolumn{2}{|c|}{ Supervisors } & \multicolumn{2}{|c|}{ Facilitators } & \multicolumn{2}{|c|}{ Delegators } & & & & \\
\hline & M & SD & M & SD & M & SD & & & & \\
\hline \multicolumn{11}{|l|}{ Theory of Planned Behavior } \\
\hline Attitudes & 19.28 & 4.48 & 19.69 & 3.90 & 19.12 & 3.63 & 1.95 & 0.14 & & 0.004 \\
\hline Subjective norms & 21.83 & 5.28 & 22.79 & 4.14 & 21.28 & 4.60 & 9.96 & $<0.001$ & $F>S, D$ & 0.018 \\
\hline Perceived behavioral control & 16.67 & 4.08 & 16.49 & 3.92 & 16.09 & 4.21 & 1.14 & 0.32 & & 0.002 \\
\hline Barriers & 18.10 & 4.25 & 18.28 & 4.11 & 19.42 & 3.80 & 6.51 & $<0.01$ & $D>F, S$ & 0.012 \\
\hline Behavioral intention & 19.26 & 4.53 & 20.14 & 4.29 & 17.53 & 4.89 & 25.05 & $<0.001$ & $F>S>D$ & 0.044 \\
\hline \multicolumn{11}{|l|}{ Psychological reactance } \\
\hline Psychological reactance & 13.79 & 6.56 & 13.06 & 5.68 & 14.69 & 6.33 & 5.63 & $<0.01$ & $D>F$ & 0.010 \\
\hline Dispositional reactance & 36.39 & 9.42 & 34.46 & 8.26 & 37.09 & 7.86 & 9.33 & $<0.001$ & $D, S>F$ & 0.017 \\
\hline
\end{tabular}

Supervisors All-in Supervisors; Facilitators Facilitators; Delegators Reluctant Delegators; $C$ post hoc Dunnett's C comparisons; $\eta^{2}=$ Partial $\eta^{2} .01=$ small, $.06=$ medium, $.14=$ large effect size 
bullying incidents. They advocated consequences that were firm enough and consistent for all students. Although they preferred that individual schools rather than school boards or government ministries of education make decisions about the adoption of $\mathrm{AB}$ programs, importance scores suggest that decision control exerted a relatively limited influence on program choices (Table 3 ).

RQ2. Is the Theory of Planned Behavior linked to latent class membership? A MANOVA across the Theory of Planned Behavior's constructs showed a significant class effect, $F(10,2148)=6.86, p<.001$. Reluctant Delegators reported more barriers to the implementation of AB programs than did All-in Supervisors or Facilitators (Table 4). Facilitators reported their decision to participate in AB programs was more likely to be influenced by individuals and organizations (Subjective Norms) than did All-in Supervisors or Reluctant Delegators. Reluctant Delegators intended to participate in fewer AB activities than All-in Supervisors who intended to participate in fewer $\mathrm{AB}$ activities than Facilitators. Educators in the Level 3 class of schools with a greater proportion of Reluctant Delegators (school Class 1) reported significantly fewer benefits to AB programs (Attitudes), were less likely to be influenced by social norms, and less confident in their ability to implement $\mathrm{AB}$ programs (Perceived Behavioral Control). Although these differences were statistically significant, effect sizes were small (Supplementary Electronic Table 4).

RQ3. Is psychological reactance linked to latent class membership? A MANOVA across dispositional reactance and psychological reactance measures showed a significant class effect $F(4,2154)=6.23, p<.001$. Reluctant Delegators reported higher dispositional reactance than did Facilitators or All-in Supervisors (Table 4). Reluctant Delegators also reported engaging in or experiencing more psychological reactance to AB programs than did Facilitators. Educators in the Level 3 class of schools with a greater proportion of Reluctant Delegators (Class 1) reported higher dispositional reactance and psychological reactance scores (Supplementary Electronic Table 4). Although these differences were statistically significant, effect sizes were small.

\section{Discussion}

This study makes three contributions to the study of the AB program design preferences of educators. First, we illustrate the use of preference modeling strategies from marketing research (Orme, 2014) and health economics (de BekkerGrob et al., 2012) to engage educators in the AB program design process. These methods, which are relatively new to the study of school-based programming, allowed us to estimate the relative importance of the individual components of hypothetical $\mathrm{AB}$ programs, identify latent classes preferring a different approach to program design, and identify correlates of segment membership. Second, we extend previous studies by applying a multi-level latent class approach to the analysis of choice data (Vermunt, 2008; Zhang, Zhang, Zhang, \& Jiao, 2014). Multi-level analysis points to a potentially important clustering of Reluctant Delegators in one class of schools. Third, this is, to our knowledge, the first study to establish empirical links between measures of dispositional and psychological reactance and membership in classes preferring different approaches to the design of AB programs. Below we consider the applied implications of our findings, revisit focus group discussions conducted prior to this study for suggestions as to why those attributes were important to educators (Cunningham et al., 2016), and examine empirical evidence regarding the impact of this set of attributes on the implementation process.

\section{Summary and Implications}

\section{Ensure Supportive Principals}

Principals exerted an important influence on $\mathrm{AB}$ program choices. Focus groups suggested that principal buy-in encouraged the level of staff participation needed to conduct AB programs (Cunningham et al., 2016). In a longitudinal study of the KiVa program, for example, teachers who evidenced high or moderate adherence, coupled with principals perceived to support the program, were more likely to remain adherent throughout the year (Haataja, Ahtola, Poskiparta, \& Salmivalli, 2015). A study of Finnish educators found that perceived head teacher support for the implementation of the KiVa $\mathrm{AB}$ program was associated with greater adherence (Ahtola et al., 2013). Adherence and program dosage, in turn, have been associated with classroom reductions in victimization (Haataja et al., 2014; Swift et al., 2017).

Educators preferred principals who provided back-up, rather than simply championing $\mathrm{AB}$ programs. Focus groups suggested that principal back-up was particularly important when dealing with confrontational students or parents (Cunningham et al., 2016). In a national sample of 2998 educators, $80 \%$ had been the targets of harassment, bullying, or violence, many by students and parents (Reddy et al., 2013). The bullying and interpersonal aggression directed at educators predicts burnout and emotional exhaustion, factors that may adversely affect the implementation of AB programs, and, ultimately, decisions to leave the profession (Reddy et al., 2013).

\section{Ensure the Support of Colleagues}

Consistent with RQ1's predictions, the support and engagement of colleagues exerted an important influence on $\mathrm{AB}$ 
program choices. In focus groups, educators suggested that having the entire staff "on board" was critical to the successful implementation of $\mathrm{AB}$ programs. This is consistent with previous studies (Cunningham et al., 2009, 2014) and a broader body of implementation science (Damschroder et al., 2009; Durlak \& DuPre, 2008). All segments preferred that colleagues both liked and participated in the program. Results, however, suggest that schools may have particular difficulty securing the support of Reluctant Delegators. This class reported more barriers to implementation, more dispositional reactance, greater reactance to $A B$ programs, and a lower intent to participate in $\mathrm{AB}$ activities. Although Reluctant Delegators constituted a relatively small class (16.9\%), the sensitivity of educators to the views of their colleagues (Cunningham et al., 2009) suggests that they might exert a significant influence on implementation decisions. Multi-level analysis finding that the concentration of Reluctant Delegators in one of the two school-level latent classes $(26 \%$ vs. $3 \%)$ suggests their influence might vary across schools. Educators in the Level 3 class of schools with a greater proportion of Reluctant Delegators (Class 1) reported higher dispositional reactance, more psychological reactance, were less likely to be influenced by social norms, and less confident in their ability to implement $\mathrm{AB}$ programs.

The preferences of Reluctant Delegators are similar to those of a previous study's Cost-Sensitive class who identified more barriers to the implementation of $A B$ programs and were less intent on participating (Cunningham et al., 2009). The stability of this three-segment latent class finding is striking. Although we recruited a new sample of educators, introduced new attributes, and incorporated levels focusing on different design issues, both studies revealed three latent classes with a small group of educators $(17 \%$ here, $16 \%$ previously) who seemed hesitant to support the implementation of AB programs(Cunningham et al., 2009).

How should schools engage Reluctant Delegators? This class valued many of the design attributes preferred by Facilitators and All-in Supervisors: principals who championed programs and backed teachers up and colleagues who liked and participated in AB programs. The Theory of Planned Behavior suggests that reducing implementation barriers and enhancing the influence of significant colleagues and administrators would increase the intent to participate. Psychological Reactance Theory, moreover, suggests that enhancing participation during the design and implementation process (Legault et al., 2011), coupled with programming encouraging an empathic response to this problem (Shen, 2010), would encourage implementation.

\section{Engage Students and Parents}

Student engagement exerted an important influence on $\mathrm{AB}$ program preferences. Focus groups suggested that, in the absence of the cooperation of students and parents, it was difficult to deal with bullying incidents (Cunningham et al., 2016). In a previous study, educators were more likely to choose $\mathrm{AB}$ programs supported by a clear majority of their students (Cunningham et al., 2009). Enlisting student bystanders is a central component of programs such as KiVa which have proved effective in reducing bullying (Salmivalli, Kärnä, \& Poskiparta, 2010). Although student engagement exerted an important influence on $\mathrm{AB}$ design preferences, mobilizing parental support and engagement was of relatively low importance to educators. Systematic reviews, nonetheless, suggest that the inclusion of parents via parent training or meetings is associated with a greater reduction in bullying and victimization (Ttofi \& Farrington, 2011).

\section{Ensure Continuity}

Consistent with previous studies (Cunningham et al., 2009, 2016), participants preferred AB initiatives providing stable programming from kindergarten to Grade 12 . Educators participating in focus groups expressed concern regarding a tendency for schools to discontinue programs in favor of new initiatives without giving potentially effective programs time to work (Cunningham et al., 2016). The importance of program stability is supported by metaanalyses finding the duration of $\mathrm{AB}$ programs to be associated with improved outcome (Ttofi \& Farrington, 2011). This attribute's high importance suggests that educators may be more likely to invest the time and effort needed to implement $A B$ programs successfully when they are confident these initiatives will be sustained.

\section{Accommodate Differing Views Regarding the Supervision of Playgrounds and Hallways}

In focus groups, educators reported difficulty detecting bullying on the playgrounds and in the hallways where these incidents occur (Cunningham et al., 2016). Vaillancourt and colleagues (2010) advocated an increase in the number of adults supervising students in high-risk areas. Systematic reviews confirm that increased supervision is associated with lower bullying and victimization (Ttofi $\&$ Farrington, 2011). The three classes, however, brought a different perspective to Recess Supervision. All-inSupervisors thought all educators should be engaged in supervision, Facilitators preferred that only $25 \%$ of educators provided supervision, and Reluctant Delegators preferred this responsibility was shifted to non-teaching 
staff. Importance scores suggest the allocation of supervisory responsibilities exerted a stronger influence on the choices of Reluctant Delegators than any other attribute. The sensitivity of Reluctant Delegators to the allocation of supervisory responsibilities emphasizes the importance of an approach to the implementation of playground monitoring strategies that engages this class.

\section{Balanced Focus on Bullying and Underlying Problems}

Educators preferred programs focusing on the underlying problems contributing to bullying. In focus groups, for example, educators discussed the influence the peer group processes that limit the extent to which students act empathically or discourage students from participating in AB program (Cunningham et al., 2016). Educators also valued $\mathrm{AB}$ programs with consequences that were firm and consistent for all students. The importance of effective consequences was a recurrent theme in focus group discussions (Cunningham et al., 2016) and is consistent with systematic reviews (Ttofi \& Farrington, 2011). A study of Grade 9 students reported that bullying was less frequent in schools that consistently enforced rules in the context of caring and respectful interactions with teachers (Gregory et al., 2010).

\section{Provide Evidence of Efficacy and Effectiveness}

Program choices were influenced by both research and personal experience supporting the effectiveness of $\mathrm{AB}$ initiatives. Experience exerted more influence on choices than scientific studies. Because teachers observe few bullying episodes (Craig, Pepler, \& Atlas, 2000), they may have difficulty evaluating the impact of the $\mathrm{AB}$ programs in their schools. Focus group participants, for example, suggested that they were not provided with convincing evidence regarding program effectiveness or that their observations provided little evidence that bullying was declining (Cunningham et al., 2016). The perception that programs are effective is important; educators who judged the KiVa program to be more effective were more likely to be members of a latent class showing high implementation (Haataja et al., 2015). By supplementing research evidence with the student-reported school climate surveys available in many jurisdictions, Boards of Education could provide local outcome data that approximate the experiential evidence that educators valued.

\section{Engage Educators in Decision Making}

All classes preferred school-based decisions regarding the adoption of $\mathrm{AB}$ programs. This is consistent with both qualitative (Cunningham et al., 2016) and quantitative studies (Cunningham et al., 2009, 2014). Focus groups thought that participatory decisions promoted the consensus needed to support implementation and decreased the pushback which may result from top-down adoption processes (Cunningham et al., 2016). In a sample of 544 US schools, a local program selection process was associated with greater implementation intensity (Payne, Gottfredson, \& Gottfredson, 2006). The choices of Reluctant Delegators were more sensitive to variations in the program selection process than were those of Facilitators and All-in Supervisors. Given higher dispositional reactance, more psychological reactance, a perception of more barriers to the implementation of $\mathrm{AB}$ programs, and a lower intent to participate, it may be particularly difficult to engage Reluctant Delegators in the planning process. Random Utility Theory suggests that $\mathrm{AB}$ programs ensuring the inclusion of high value attributes would compensate for the disutility attributable to a mandated program selection process.

\section{Limitations}

The results of this study need to be considered in the context of several limitations. First, this research was conducted in a unionized public educational system located in an economically and culturally diverse Canadian community. The generalizability of these findings is unclear. Second, although only 48 of the 70 schools identified as potential recruiting sites participated, the demographics of the general areas in which participating and nonparticipating schools were located did not differ significantly. Third, our approach to anonymous coding of schools did not allow us to link school demographics to Level 3 class membership. Describing the characteristics of schools in latent classes at Level 3 would be an important direction for future studies. Fourth, we studied the influence of 12 4-level AB program design and implementation attributes that emerged as recurrent themes from focus groups with educators. Our models are limited by attributes that were not included. Last, although we report good internal consistency for the Theory of Planned Behavior and psychological reactance scales, a more detailed presentation of the psychometric properties of these scales goes beyond the current manuscript.

\section{Conclusion}

Educators agree on the importance of contextual support, student engagement, firm and consistent consequences, and stable programming. These design preferences are supported by systematic reviews and implementation research. Latent 
class analysis points to classes of educators with diverging views regarding strategically important dimensions of program design, differences in Attitudes that may influence the intent to participate in or react to program implementation, and the potential clustering of classes of educators within schools.

Acknowledgments The authors express their appreciation for the research support provided by Stephanie Mielko and Yvonne Chen. We would like to thank the educators who shared their design perspectives and the school boards that enabled this research. Dr. Jay Magidson from Statistical Innovations provided statistical consultation. Thipiga Sivayoganathan provided editorial support. This research was supported by a grant from the Canadian Institutes of Health Research (MOP 123437). C. Cunningham's participation was supported by the Jack Laidlaw Chair in Patient-Centered Health Care. T. Vaillancourt's participation was supported by a Canada Research Chair.

\section{Compliance with Ethical Standards}

Ethical Approval This study was approved by the Hamilton Integrated Research Ethics Board (\#12-477) and the participating school boards. The study was conducted in accordance with the 1964 Helsinki Declaration and its later amendments or comparable ethical standards. Informed consent was obtained from all individual participants included in the study. Potential conflict of interest: C. Cunningham has received royalties for large group parenting program workshops and materials.

Open Access This article is distributed under the terms of the Creative Commons Attribution 4.0 International License (http://creativeco mmons.org/licenses/by/4.0/), which permits unrestricted use, distribution, and reproduction in any medium, provided you give appropriate credit to the original author(s) and the source, provide a link to the Creative Commons license, and indicate if changes were made.

\section{References}

Ahtola, A., Haataja, A., Kärnä, A., Poskiparta, E., \& Salmivalli, C. (2013). Implementation of anti-bullying lessons in primary classrooms: How important is head teacher support? Educational Research, 55(4), 376-392. https://doi.org/10.1080/00131 881.2013.844941.

Ajzen, I. (1991). The theory of planned behavior. Organizational Behavior and Human Decision Processes, 50(2), 179-211.

Ball, H., \& Goodboy, A. K. (2014). An experimental investigation of the antecedents and consequences of psychological reactance in the college classroom. Communication Education, 63(3), 192209. https://doi.org/10.1080/03634523.2014.918634.

Bauman, S., Rigby, K., \& Hoppa, K. (2008). US teachers' and school counsellors' strategies for handling school bullying incidents. Educational Psychology, 28(7), 837-856. https://doi. org/10.1080/01443410802379085.

Berlin, K. S., Williams, N. A., \& Parra, G. R. (2014). An introduction to latent variable mixture modeling (part 1): Overview and cross-sectional latent class and latent profile analyses. Journal of Pediatric Psychology, 39(2), 174-187. https://doi.org/10.1093/ jpepsy/jst084.

Boulton, M. J. (2014). Teachers' self-efficacy, perceived effectiveness beliefs, and reported use of cognitive-behavioral approaches to bullying among pupils: Effects of in-service training with the I DECIDE program. Behavior Therapy, 45(3), 328-343. https:// doi.org/10.1016/j.beth.2013.12.004.

Bozionelos, G., \& Bennett, P. (1999). The theory of planned behaviour as predictor of exercise: The moderating influence of beliefs and personality variables. Journal of Health Psychology, 4(4), 517-529. https://doi.org/10.1177/135910539900400406.

Brehm, S. S., \& Brehm, J. W. (1981). Psychological reactance: A theory of freedom and control. New York: Academic Press.

Bridges, J. F., Hauber, A. B., Marshall, D., Lloyd, A., Prosser, L. A., Regier, D. A., et al. (2011). Conjoint analysis applications in health-A checklist: A report of the ISPOR Good Research Practices for Conjoint Analysis Task Force. Value in Health, 14, 403-413. https://doi.org/10.1016/j.jval.2010.11.013.

Caruso, E. M., Rahnev, D. A., \& Banaji, M. R. (2009). Using conjoint analysis to detect discrimination: Revealing covert preferences from overt choices. Social Cognition, 27(1), 128-137. https://doi. org/10.1521/soco.2009.27.1.128.

Chorpita, B. F., Park, A., Tsai, K., Korathu-Larson, P., Higa-McMillan, C. K., Nakamura, B. J., et al. (2015). Balancing effectiveness with responsiveness: Therapist satisfaction across different treatment designs in the Child STEPs randomized effectiveness trial. Journal of Consulting and Clinical Psychology, 83(4), 709-718. https ://doi.org/10.1037/a0039301.

Chrzan, K. (2010). Using partial profile choice experiments to handle large numbers of attributes. International Journal of Market Research, 52(6), 827-840. https://doi.org/10.2501/S147078531 0201673

Craig, W., Pepler, D. J., \& Atlas, R. (2000). Observations of bullying in the playground and in the classroom. School Psychology International, 21(1), 22-36. https://doi.org/10.1177/0143034300211002.

Crothers, L. M., \& Kolbert, J. B. (2004). Comparing middle school teachers' and students' views on bullying and anti-bullying interventions. Journal of School Violence, 3, 17-32. https://doi. org/10.1300/J202v03n01_03.

Cunningham, C., Barwick, M., Short, K., Chen, Y., Rimas, H., Ratcliffe, J., \& Mielko, S. (2014). Modeling the mental health practice change preferences of educators: A discrete-choice conjoint experiment. School Mental Health. https://doi.org/10.1007/s1231 0-013-9110-8.

Cunningham, C., Rimas, H., Mielko, S., Mapp, C., Cunningham, L., Buchanan, D., ... Marcus, M. (2016). What limits the effectiveness of antibullying programs? A thematic analysis of the perspective of teachers. Journal of School Violence, 15(4), 460-482. https ://doi.org/10.1080/15388220.2015.1095100.

Cunningham, C., Vaillancourt, T., Rimas, H., Deal, K., Cunningham, L., Short, K., \& Chen, Y. (2009). Modeling the bullying prevention program preferences of educators: A discrete choice conjoint experiment. Journal of Abnormal Child Psychology, 37, 929-943. https://doi.org/10.1177/0143034300211002.

Damschroder, L. J., Aron, D. C., Keith, R. E., Kirsh, S. R., Alexander, J. A., \& Lowery, J. C. (2009). Fostering implementation of health services research findings into practice: A consolidated framework for advancing implementation science. Implementation Science: $I S, 4$, 50. https://doi.org/10.1186/1748-5908-4-50.

de Bekker-Grob, E. W., Ryan, M., \& Gerard, K. (2012). Discrete choice experiments in health economics: A review of the literature. Health Economics, 21(2), 145-172. https://doi.org/10.1002/ hec. 1697.

DeLuca, P. F., Johnston, N., \& Buist, S. (2012). The Code Red Project: Engaging communities in health system change in Hamilton, Canada. Social Indicators Research, 108(2), 317-327. https://doi. org/10.1007/s11205-012-0068-y.

Durlak, J. A., \& DuPre, E. P. (2008). Implementation matters: A review of research on the influence of implementation on program outcomes and the factors affecting implementation. American 
Journal of Community Psychology, 41, 327-350. https://doi. org/10.1007/s10464-008-9165-0.

Dziak, J. J., Coffman, D. L., Lanza, S. T., Li, R., \& Jermiin, L. S. (2019). Sensitivity and specificity of information criteria. Briefings in Bioinformatics. https://doi.org/10.1093/bib/bbz016.

Gregory, A., Cornell, D., Fan, X., Sheras, P., Shih, T.-H., \& Huang, F. (2010). Authoritative school discipline: High school practices associated with lower bullying and victimization. Journal of Educational Psychology, 102(2), 483-496. https://doi.org/10.1037/ a0018562.

Gunter, R. W., \& Whittal, M. L. (2010). Dissemination of cognitivebehavioral treatments for anxiety disorders: Overcoming barriers and improving patient access. Clinical Psychology Review, 30(2), 194-202. https://doi.org/10.1016/j.cpr.2009.11.001.

Haataja, A., Ahtola, A., Poskiparta, E., \& Salmivalli, C. (2015). A process view on implementing an antibullying curriculum: How teachers differ and what explains the variation. School Psychology Quarterly, 30(4), 564. https://doi.org/10.1037/spq0000121.

Haataja, A., Voeten, M., Boulton, A. J., Ahtola, A., Poskiparta, E., \& Salmivalli, C. (2014). The KiVa antibullying curriculum and outcome: Does fidelity matter? Journal of School Psychology, 52(5), 479-493. https://doi.org/10.1016/j.jsp.2014.07.001.

Hauber, B., Gonzalez, J., Groothuis-Oudshoorn, C., Prior, T., Marshall, D., Cunningham, C., ... Bridges, J. (2016). Statistical methods for the analysis of discrete-choice experiments: A report of the ISPOR Conjoint Analysis Good Research Practices Task Force. Value in Health, 19(4), 300-315. https://doi.org/10.1016/j. jval.2016.04.004.

Hauser, J. R. (2014). Consideration-set heuristics. Journal of Business Research, 67(8), 1688-1699. https://doi.org/10.1016/j.jbusr es.2014.02.015.

Hymel, S., \& Swearer, S. M. (2015). Four decades of research on school bullying: An introduction. The American Psychologist, 70(4), 293-299. https://doi.org/10.1037/a0038928.

Johnson, F. R., Lancsar, E., Marshall, D., Kilambi, V., Mühlbacher, A., Regier, D. A., et al. (2013). Constructing experimental designs for discrete-choice experiments: Report of the ISPOR Conjoint Analysis Experimental Design Good Research Practices Task Force. Value in Health, 16(1), 3-13. https://doi.org/10.1016/j. jval.2012.08.2223.

Johnson, L., Wehby, J., Symons, F. J., Moore, T. C., Maggin, D. M., \& Sutherland, K. S. (2014). An analysis of preference relative to teacher implementation of intervention. The Journal of Special Education, 48(3), 214-224. https://doi.org/10.1177/0022466913 475872.

Lanza, S. T., \& Rhoades, B. L. (2013). Latent class analysis: An alternative perspective on subgroup analysis in prevention and treatment. Prevention Science, 14(2), 157-168. https://doi. org/10.1007/s11121-011-0201-1

Larson, K. E., \& Bradshaw, C. P. (2017). Cultural competence and social desirability among practitioners: A systematic review of the literature. Children and Youth Services Review, 76, 100-111. https://doi.org/10.1016/j.childyouth.2017.02.034.

Legault, L., Gutsell, J., \& Inzlicht, M. (2011). Ironic effects of antiprejudice messages: How motivational interventions can reduce (but also increase) prejudice. Psychological Science, 22(12), 1472-1477. https://doi.org/10.1177/0956797611427918.

McDougall, P., \& Vaillancourt, T. (2015). Long-term adult outcomes of peer victimization in childhood and adolescence: Pathways to adjustment and maladjustment. The American Psychologist, 70(4), 300-310. https://doi.org/10.1037/a0039174.

Nylund, K., Asparouhov, T., \& Muthén, B. O. (2007). Deciding on the number of classes in latent class analysis and growth mixture modeling: A Monte Carlo simulation study. Structural Equation Modeling, 14(4), 535-569. https://doi.org/10.1080/1070551070 1575396.
Olweus, D. (1994). Bullying at school: Basic facts and effects of a school based intervention program. Journal of Child Psychology and Psychiatry, 35, 1171-1190. https://doi. org/10.1111/j.1469-7610.1994.tb01229.x.

Orme, B. K. (2014). Getting started with conjoint analysis: Strategies for product design and pricing research (4th ed.). Madison, WI: Research Publishers.

Payne, A. A., Gottfredson, D. C., \& Gottfredson, G. D. (2006). School predictors of the intensity of implementation of school-based prevention programs: Results from a national study. Prevention Science, 7, 225-237. https://doi.org/10.1007/s11121-006-0029-2.

Phillips, K. A., Johnson, F. R., \& Maddala, T. (2002). Measuring what people value: A comparison of "attitude" and "preference" surveys. Health Services Research, 37(6), 1659-1679. https://doi. org/10.1111/1475-6773.01116.

Powell, B. J., Beidas, R. S., Lewis, C. C., Aarons, G. A., McMillen, J. C., Proctor, E. K., et al. (2015). Methods to improve the selection and tailoring of implementation strategies. The Journal of Behavioral Health Services \& Research.. https://doi.org/10.1007/ s11414-015-9475-6.

Reddy, L. A., Espelage, D., McMahon, S. D., Anderman, E. M., Lane, K. L., Brown, V. E., et al. (2013). Violence against teachers: Case studies from the APA Task Force. International Journal of School \& Educational Psychology, 1(4), 231-245. https://doi. org/10.1080/21683603.2013.837019.

Rosenberg, B. D., \& Siegel, J. T. (2017). A 50-year review of psychological reactance theory: Do not read this article. Motivation Science. . https://doi.org/10.1037/mot0000091.

Salmivalli, C., Kärnä, A., \& Poskiparta, E. (2010). Development, evaluation, and diffusion of a national anti-bullying program, KiVa. In B. Doll, W. Pfohl, \& J. Yoon (Eds.), Handbook of youth prevention science (pp. 238-252). New York: Routledge.

Shen, L. (2010). Mitigating psychological reactance: The role of message-induced empathy in persuasion. Human Сотmиnication Research, 36(3), 397-422. https://doi.org/10.111 1/j.1468-2958.2010.01381.x.

Shen, L., \& Dillard, J. P. (2005). Psychometric properties of the Hong psychological reactance scale. Journal of Personality Assessment, 85(1), 74-81. https://doi.org/10.1207/s15327752jpa8501_07.

Swift, L. E., Hubbard, J. A., Bookhout, M. K., Grassetti, S. N., Smith, M. A., \& Morrow, M. T. (2017). Teacher factors contributing to dosage of the KiVa anti-bullying program. Journal of School Psychology, 65, 102-115. https://doi.org/10.1016/j.jsp.2017.07.005.

Ttofi, M. M., \& Farrington, D. P. (2011). Effectiveness of school-based programs to reduce bullying: A systematic and meta-analytic review. Journal of Experimental Criminology, 7(1), 27-56. https ://doi.org/10.1007/s11292-010-9109-1.

Vaillancourt, T., Brittain, H., Bennett, L., Arnocky, S., McDougall, P., Hymel, S., ... Cunningham, L. J. (2010). Places to avoid: Population-based study of student reports of unsafe and high bullying areas at school. Canadian Journal of School Psychology, 25(1), 40-54. https://doi.org/10.1177/0829573509358686.

Veenstra, R., Lindenberg, S., Huitsing, G., Sainio, M., \& Salmivalli, C. (2014). The role of teachers in bullying: The relation between antibullying attitudes, efficacy, and efforts to reduce bullying. Journal of Educational Psychology, 106(4), 1135. https://doi. org/10.1037/a0036110.

Vermunt, J. (2008). Latent class and finite mixture models for multilevel data sets. Statistical Methods in Medical Research, 17(1), $33-51$.

Vermunt, J., \& Magidson, J. (2005). Latent GOLD ${ }^{\circledR}$ Choice 4.0 user's manual. Belmont MA: Statistical Innovations Inc.

Wittink, D. R., Krishnamurthi, L., \& Reibstein, D. J. (1990). The effect of differences in the number of attribute levels on conjoint results. Marketing Letters, 1(2), 113-123. https://doi.org/10.1007/BF004 35295. 
Yeager, D. S., Fong, C. J., Lee, H. Y., \& Espelage, D. L. (2015). Declines in efficacy of anti-bullying programs among older adolescents: A developmental theory and a three-level meta-analysis. Journal of Applied Developmental Psychology, 37, 36-51. https ://doi.org/10.1016/j.appdev.2014.11.005.

Zhang, J., Zhang, M., Zhang, W., \& Jiao, C. (2014). Model selection for complex multilevel latent class model. Communications in Statistics - Simulation and Computation, 43(4), 838-850. https:// doi.org/10.1080/03610918.2012.718836.

Zhou, M., Thayer, W. M., \& Bridges, J. F. P. (2018). Using latent class analysis to model preference heterogeneity in health: A systematic review. PharmacoEconomics, 36(2), 175-187. https ://doi.org/10.1007/s40273-017-0575-4.

Publisher's Note Springer Nature remains neutral with regard to jurisdictional claims in published maps and institutional affiliations. 